\title{
First report on the bacterial community composition, diversity, and functions in Ramsar site of Central Himalayas, Nepal
}

\section{Namita Paudel Adhikari}

Chinese Academy of Sciences

\section{Subash Adhikari}

Government of Nepal

Keshao Liu

Chinese Academy of Sciences

\section{Yuying Chen}

Chinese Academy of Sciences

\section{Birendra Prasad Sharma}

Chinese Academy of Sciences

\section{Ganesh Paudel}

Tribhuvan University

\section{Yongqin Liu ( $\nabla$ yqliu@itpcas.ac.cn )}

Chinese Academy of Sciences https://orcid.org/0000-0003-2876-7484

\section{Research Article}

Keywords: Bacterial community composition, diversity, functions, Ramsar site, Wetlands

Posted Date: February 7th, 2022

DOI: https://doi.org/10.21203/rs.3.rs-1294470/v1

License: (c) (1) This work is licensed under a Creative Commons Attribution 4.0 International License. Read Full License 


\section{Abstract}

Ramsar sites are wetlands of international importance covering major ecosystem processes and services. Bacterial communities play a significant role in the lacustrine ecosystem and release major nutrients in wetlands, yet little is known about controls over their distribution and abundance from the Ramsar site of Central Himalayas, Nepal. Thus, we studied the bacterial community composition, diversity, and functions in the wetlands (designed as Ramsar site, Ramsar no 2257) during the autumn and spring by using $16 \mathrm{~S}$ rRNA gene-based Illumina MiSeq sequencing. We reported a pronounced variation in water physicochemical and biological properties (temperature, $\mathrm{pH}, \mathrm{Chl} a, \mathrm{DOC}$, and TN), bacterial diversity, and community composition. Alpha diversity was highest in Autumn while beta diversity (based on unifrac distance) in spring. Our results uncovered the effect of nutrients on bacterial abundance, richness, and community composition. Most unique operational taxonomic units (OTUs) (58\%) belonged to autumn, while $14 \%$ of the OTUs were shared between spring and autumn. Planctomycetes and Bacteroidetes dominated the spring exclusive OTUs; meanwhile, Actinobacteria dominated the autumn exclusive OTUs. Bacteria in these wetlands exhibited divergent roles; however, a higher abundance of bacteria associated with animal parasites and human pathogens indicated a public health risk. By disclosing the seasonal variation of bacterial community and their relationship with environmental factors, this first-hand work in the Ramsar site of Nepal will develop a baseline dataset for the scientific community that will assist in understanding the wetlands microbial ecology and biogeography.

\section{Introduction}

Ramsar sites (wetlands of international importance) are the most important ecosystems and biodiversity hot spots (Paudel et al. 2017). They play a pivotal role in the ecological processes supporting biodiversity and maintaining environmental health because they are highly dynamic ecosystems. Wetlands make up only around $5 \%$ of the Earth's surface area, yet they provide over $40 \%$ of ecosystem processes and services (Pendleton et al. 2020). It is a highly productive ecosystem due to fast recycling and metabolically active aerobic and anaerobic bacteria (Bodelier and Dedysh 2013; Huang et al. 2018). Lakes are the natural wetlands covering a significantly prominent place among the inland water bodies and have been most extensively altered by various natural and anthropogenic activities (Carpenter et al. 2011; Zhang et al. 2018; Chen et al. 2020). Due to short generation time and active metabolism, bacterial communities are a dynamic component of lake wetlands playing a dominant role in biogeochemical cycles and ecological processes (Fisher et al. 2015; Huang et al. 2018; Adhikari et al. 2019; Zeng et al. 2019).

The abundance of heterotrophic bacteria in the wetlands represents a balance between growth and loss rates (Gurung et al. 2010). Bacterial community composition and dynamics of lake wetlands are governed by physicochemical factors, for instance, temperature, $\mathrm{pH}$, water transparency, nutrients (inorganic and organic substrates) (Dai et al. 2015), and phenomena like predation and lysis (Gurung et al. 2010; Kong et al. 2018). Moreover, the abundance of grazers and bacteriophages also affects bacterial diversity and composition (Sigee 2005). Aquatic microbial communities are highly susceptible to 
environmental change and respond rapidly by altering their composition and diversity (Zeng et al. 2019). Seasonal variation of bacterial communities in lacustrine ecosystems results from changes in water physicochemical properties, available nutrients, and phytoplankton blooming (Tang et al. 2015; Kong et al. 2018; Zhang et al. 2019; Zhu et al. 2019). It leads to shifts in bacterial community composition that ultimately result in the fluctuation of roles and their ecosystem functioning.

Detailed information on the diversity, specific functions, and ecology of bacterial communities is instantly essential for the sustainable management of the ecosystem (Hahn 2006). In Nepal's central Himalayas, the scientific study of bacterial community composition and diversity in aquatic ecosystems using the high coverage next-generation sequencing method is poorly understood. The first study was reported from the trans-Himalayan Koshi river (Paudel Adhikari et al. 2019), which indicated the limitation of the study. To develop the baseline dataset for the scientific community linking environment and bacterial community, the present study discusses the seasonal variation of bacterial community composition, diversity, and functions in the lake wetlands (designed as Ramsar site) from central Himalayas Nepal. It is located on the windward side of the Himalayas with a subtropical climate in a densely populated area (Konda et al. 1988). Understanding the community composition, diversity, and functions on a seasonal basis is essential to comprehend the influence of anthropogenic activities on bacterial diversity. The objectives of the study are to understand (1) the seasonal variation in bacterial community composition and diversity in the Ramsar site of central Himalayas, Nepal, (2) the environmental factors affecting the bacterial biodiversity, and (3) the ecological and pathogenic functions of bacteria. The findings from the aforementioned objectives would way forward limnologist to study wetland ecosystem as ecological processes shaping bacterial communities is crucial for aquatic microbial ecology and biogeography.

\section{Materials And Methods}

\section{Study area}

The study area $\left(28^{\circ} 7^{\prime}-28^{\circ} 12^{\prime} \mathrm{N}\right.$ to $\left.84^{\circ} 5^{\prime}-84^{\circ} 10^{\prime} \mathrm{E}\right)$ is located in the foothills of central Himalayas, Nepal. It has four distinct seasons (spring: March-May, summer: June - August, autumn: September - November, and winter: December - February) and receives $78 \%$ of annual precipitation in the summer monsoon, with the highest rainfall in July (Dahal et al. 2016, Paudel et al. 2017). However, the onset of monsoon starts earlier in May (Panthi et al. 2015). The wetlands (lake cluster) were designated as Ramsar sites (Ramsar no 2257) of international importance in 2016 (Paudel et al. 2017). Being rich in several water bodies and having a beautiful view of snow-capped mountains, the Ramsar site is the tourism hub (Paudel et al. 2017). Due to rapid urban development, tourism (Fig. S1), the study area receives pollutants from point and non-point sources. The lake cluster is eutrophic, surrounded by forest, farmland, and commercial hotels, and fed by streams from nearby catchments (Paudel et al. 2017). It plays a significant part in people's livelihood and supports groundwater recharge, flood control, and sediment. It also provides irrigation, wetland resources, fishing, religious locations, and tourism opportunities. Moreover, the wetlands aid in the maintenance of local hydrology and ecosystem. 


\section{Sample collection}

The fieldwork was conducted during November 2017 and May 2018, representing the autumn and spring season, respectively (Fig. 1). $2.5 \mathrm{~L}$ of near-surface (about $15 \mathrm{~cm}$ under the surface) water was collected at each sampling site. Triplicate of $2 \mathrm{~mL}$ aliquots from each sample was fixed immediately in $1.5 \%$ glutaraldehyde for bacterial enumeration. One litre of water was filtered through pre-combusted $\left(400{ }^{\circ} \mathrm{C}\right.$ for four $h$ ) GF/F filters. One hundred $\mathrm{mL}$ of the filtrate was stored in amber-coloured glass bottles ( $1 \%$ hydrochloric acid leached, deionized water rinsed, and combusted) for dissolved organic carbon (DOC) and total nitrogen (TN) analysis (Paudel Adhikari et al. 2019). Water samples for DNA extraction were prefiltered through sterile cheesecloth for retaining substances with the size $\geq 20 \mu \mathrm{m}$, including algal biomass, small stones, and plant debris (Crump et al. 1999, Staley et al. 2013). One litre of pre-filtered water sample was passed through a $2 \mu \mathrm{m}$ polycarbonate membrane (Millipore, USA), and the filter was used for DNA extraction. Water sampling was accompanied within a day (each season). Water samples and filters were stored in incubators with ice bags to maintain a low temperature during transportation to the laboratory. Soon after arriving at the laboratory, samples were stored at $-80^{\circ} \mathrm{C}$ until analysis (within 30 days).

\section{Physicochemical and biological analyses}

Water physicochemical properties like temperature, $\mathrm{pH}$, electrical conductivity (EC), total dissolved solids (TDS), and Chlorophyll a (Chl a) were recorded in-situ with a multiprobe Water Quality Sonde (YSI Inc., USA). Concentrations of DOC and TN were measured with a TOC-L (Shimadzu Corp., Japan) following the distributor's protocol. Flow cytometry (Beckman Coulter, Epics Altra II) was used to measure bacterial abundance using SYBR 140 Green I (Molecular Probes) nucleic acid stain at a final concentration of one part in $1.0 \times 10^{4}$ (Paudel Adhikari et al 2019).

\section{DNA extraction, bacterial 16S rRNA amplification, and Illumina MiSeq sequencing}

Community DNA was extracted from the biomass retained in $0.2 \mu \mathrm{m}$ membrane filters. Filters were aseptically cut into small pieces (approximately $2 \mathrm{~mm}$ ) using sterilized scissors and forceps. Other protocols were followed as indicated in the FastDNA® Spin kit (MP Biomedicals, Santa Ana, CA). Spectrophotometry (NanoDrop ND 2000, Thermo Scientific, DE, USA) assessed DNA quality and quantity. Primer pairs for Illumina sequencing were used in Caporaso et al. (2012). The detailed information regarding PCR amplification, gel-purification, and sequencing procedures has been previously explained (Paudel Adhikari et al. 2019). The 16S rRNA sequences are uploaded to the NCBI SRA database (BioProject accession number: PRJNA 623054). 


\section{Processing of the sequence data}

$5^{\prime}$ and $3^{\prime}$ end of raw sequence data were assembled using Fast Length Adjustment of Short reads (FLASH) software version 1.2.9 (Mago ${ }^{\prime} \mathrm{c}$ and Salzberg 2011). Raw FASTQ files were processed with the Quantitative Insights into Microbial Ecology (QIIME) v1.9.0 (Caporaso et al. 2010). As explained in N. P. Adhikari et al. (2019b), quality control was performed. Chimeric sequences were removed using USEARCH (Edgar 2010). Bacterial sequences were clustered into Operational Taxonomic Units (OTUs) at 97\% pairwise identity using the 'pick_de_novo otus.py' script with the uclust algorithm (Edgar 2010). QIIME uses the Ribosomal Database Project (RDP) classifier for assigning taxonomic data to each representative sequence (Caporaso et al. 2010).

\section{Statistical Analysis}

Bacterial alpha diversity estimates, i.e., Shannon diversity index, Pielou's evenness, and Chao1 richness, were calculated with the 'vegan' package in the R-environment (Team 2014). The Kruskal-Wallis test compared the water physicochemical properties and bacterial alpha diversity indices in the autumn and spring season. It is a non-parametric statistical test used to determine a statistically significant difference between two or more groups, mainly when an extreme deviation of data from the normal distribution (MacFarland T.W. 2016, Adhikari et al. 2021). Spearman's rank correlation was used to assess the correlation between two independent groups. The percentage of shared and unique OTUs in each season was calculated using the package 'Venn diagram' in R (Chen and Boutros 2011). Non-metric multidimensional scaling (NMDS) based on weighted UniFrac distance was used to visualize the pattern in microbial community composition. It is a popular beta-diversity metric used in ecological studies (Wang et al 2016). Dissimilarity tests like multiresponse permutation procedure (MRPP), analysis of similarities (ANOSIM), and non-parametric multivariate analysis of variance (perMANOVA) with Adonis function were then employed to evaluate the significance of the differences found between spring and autumn bacterial communities (Anderson 2001). Similarity percentage (SIMPER) analysis in PAST v3.06 (Hammer et al 2001) was used to identify the OTUs responsible for the similarity and dissimilarity observed in autumn and spring community composition. A distance-based multivariate linear model (DISTLM) based on weighted UniFrac distance was performed in the DISTLM_forward3 program for determining the environmental factors responsible for the variation of bacterial community composition.

For exploring the relationship of water physicochemical properties, nutrients, productivity, and bacterial abundance on the bacterial richness and community composition, we used PLS-PM in the R package 'plspm'(V0.4.7) (Sanchez 2013). This method is known as the partial least squares approach to structural equation modeling and allows the estimation of complex cause-effect relationships (Wang et al. 2016). Five latent variables were used: water physicochemical properties (the measured water temperature, $\mathrm{pH}, \mathrm{EC}$, and TDS), nutrients (DOC and TN), lake primary productivity (Chlorophyll a), bacterial abundance, richness, and community composition. One thousand bootstraps were used to validate the estimates of path coefficients and the coefficients of determination while running PLS-PM. Coefficients 
represent the direction and strength of the linear relationships between variables or the direct effects. Models with different structures were evaluated using the goodness of fit statistic (Wang et al. 2016).

The z-score transformation was used to standardize environmental variables to meet the normality and homogenization of the variance. The statistical analyses and graphical illustrations were performed using $\mathrm{R}$ programming unless otherwise indicated (version 3.6.2, R Foundation for Statistical Computing, Vienna, Austria).

\section{Functional analysis}

Functional annotation of prokaryotic taxa (FAPROTAX) was performed to investigate the potential functions of bacterial communities on the normalized OTU table. It is a promising tool for predicting functional groups, metabolic phenotypes or ecologically relevant functions of prokaryotes derived from 16S rRNA amplicon sequencing (Sansupa et al 2021). It is a manually constructed database with a Python script for converting OTU tables into putative functional tables based on the taxa identified in a sample (Louca et al. 2016). Functions predicted in FAPROTAX focus on marine and lake biogeochemistry (Louca et al. 2016).

\section{Results}

\section{Seasonal variation of geochemical properties and bacterial abundance}

Water temperature and $\mathrm{pH}$ ranged from $20.3-31^{\circ} \mathrm{C}$ and $6.2-8.6$, respectively. The concentrations of DOC and TN varied from $0.7-8.9 \mathrm{mg} \mathrm{L}^{-1}$ and $0.2-3.9 \mathrm{mg} \mathrm{L}^{-1}$, respectively. The value of EC and TDS ranged from $38-115.1 \mathrm{mg} \mathrm{L}^{-1}$ and $19-58.4 \mathrm{mg} \mathrm{L}^{-1}$, respectively. The concentration of $\mathrm{Chl}$ a ranged from 0.5 -

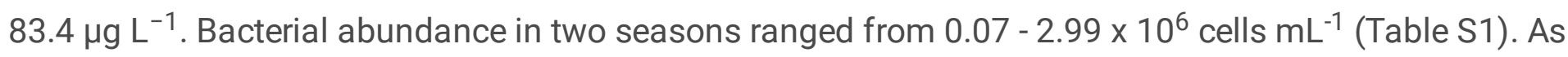
expected, the maximum value of bacterial abundance was measured in the spring season. Comparison based on the Kruskal-Wallis test indicated a significant $(\mathrm{p}<0.05)$ difference in temperature, $\mathrm{pH}, \mathrm{Chl} a$, DOC, and TN in spring and autumn (Fig. S2).

An interesting correlation between water temperature, $\mathrm{Chl} a$ and water nutrients was reported in our study. Temperature showed significant positive correlation with DOC $(r=0.55, P<0.05)$ and $\mathrm{Chl} a(r=0.67, P$ $<0.01)$. Chl a showed significant positive correlation with DOC $(r=0.72, P<0.001)$ and TN $(r=0.50, P$ $<0.05)$, while it was significantly negatively correlated with TDS $(r=-0.47, P<0.05)$. EC and TDS correlated strongly with each other i.e., $(r=0.99, P<0.001)$ (Fig. S3).

\section{Variations in diversity and community composition}


After removing chimeric sequences, 753,880 high quality reads were obtained, with $30,395-54,782$ sequences $($ mean $=41882 \pm 6457)$ in each sample.

Three measures of alpha diversity indices representing diversity (Shannon diversity index), evenness (Pielou's evenness), and richness (Chao1 richness) were used. In study sites, the diversity, evenness, and richness ranged from $5.3-8.3,0.50-0.73$, and 1539 - 4810, respectively (Fig. 2). Values of diversity and evenness were reported to be significantly $(p<0.001)$ higher in autumn, meanwhile, the richness was significantly $(p<0.05)$ higher in spring.

Clear separation of samples based on the different seasons was observed in the ordination space of NMDS (Fig. 3a). Dissimilarity tests also confirmed the pattern, showing significantly distinct bacterial composition in spring and autumn bacterial communities (MRPP, ANOSIM, and perMANOVA, all $P=$ 0.001 , Table S2). Thus, pronounced seasonal variation of BCC was observed in Ramsar sites of the Central Himalayas. Furthermore, a comparison of bacterial community dissimilarity (Bray-Curtis distance) in two seasons uncovered that bacterial $\beta$-diversity in autumn was significantly higher than that in the spring $(p<0.001)$ (Fig. 3b).

\section{Distribution of taxa in autumn and spring}

Out of 16,599 OTUs obtained in this study, a maximum number of unique OTUs were found in the autumn, i.e., $58 \%$ (9630). $28 \%$ (4652) of the total OTUs were unique in spring. Meanwhile, the proportion of shared OTUs in autumn and spring was 14\% (2317) (Fig 4).

Sequences belonging to Gammaproteobacteria (25\%) and Actinobacteria (7\%) dominated the shared OTUs in the autumn and spring seasons (Fig. 5a). In autumn, Actinobacteria (11\%) dominated the unique OTUs (Fig. 5b). However, sequences belonging to Planctomycetes (22\%) and Bacteroidetes (10\%) dominated the unique OTUs in spring (Fig. 5c). SIMPER analysis revealed that 12 OTUs explained for $33 \%$ of bacterial community dissimilarity in two seasons (contribution cutoff $>1 \%$ ) (Fig. S4). Of them, 5 OTUs belonged to Gammaproteobacteria, 3 OTUs belonged to Actinobacteria, 2 OTUs belonged to Verrucomicrobia, and each in Alphaproteobacteria and Planctomycetes. Among all indicator OTUs, the most remarkable was OTU0, classified into Acinetobacter johnsonii. This OTU showed an average abundance of $34 \%$ in spring while $3 \%$ in autumn, contributing to $18 \%$ of the total bacterial community dissimilarity.

\section{Water physicochemical properties influencing bacterial biodiversity}

Bacterial abundance showed a significant positive correlation with DOC $(r=0.67, P<0.01)$ (Fig. S4). Shannon diversity index displayed a significant positive correlation with $\mathrm{pH}(r=0.52, P<0.05)$, but negative with $\mathrm{Chl} a(r=-0.47, P<0.05)$, and temperature $(r=-0.78, P<0.001)$. Evenness showed 
significant negative correlation with temperature $(r=-0.70, P<0.001), \mathrm{DOC}(r=-0.47, P<0.05)$ and $\mathrm{Chl} a$ $(r=-0.58, P<0.05)$, respectively. Richness presented significant positive correlation with $\mathrm{Chl} a(r=0.48, P$ $<0.05)$, and DOC $(r=0.48, P<0.05)$, respectively (Fig. S5).

According to the forward selection of environmental variables (sequential test in DISTLM_forward program, 999 permutations), temperature and TDS were the significant environmental factors explaining the BCC variation. In total, all these factors explained $26 \%$ of BCC variation (Table 1). Furthermore, PLSPM illustrated the direct and indirect effects of different environmental factors in bacterial community composition and richness. Goodness of fit (GoF) statistics values for BCC and richness were 0.54 and 0.52 , respectively. GoF values signified the ease of our hypothetical path model. Water physicochemical properties negatively affected nutrients, productivity, and bacterial abundance (i.e., a total effect of -0.32 , -0.41 , and -0.25 , respectively). Meanwhile, nutrients positively affected productivity (a total effect of 0.81 ) and bacterial abundance (0.65). Wetlands productivity showed a positive effect on bacterial abundance (0.23). For bacterial community composition, the total effects of physicochemical properties, nutrients, productivity, and bacterial abundance were $0.13,0.42,0.66$, and 0.22 , respectively. For richness, the total effects of physicochemical properties, nutrients, productivity, and bacterial abundance were $0.34,0.60$, -0.10 , and -0.20 , respectively (Fig. 6 ).

\section{Potential functions of microbial communities in two seasons}

A comprehensive assignment of microbial taxa to function was performed to identify bacterial potential ecological and pathogenic roles in two seasons. The result of predicted functions indicated that the majority of putative functions were enriched for aerobic chemoheterotrophy (16\%), chemoheterotrophy $(14 \%)$, animal parasites or symbionts (9\%), aromatic compound degradation (8\%), and human pathogens (8\%) (Fig. 7). We also noticed that the abundance of bacteria belonging to all the aforementioned putative functions was higher in spring. Acinetobacter, Enhydrobacter, Sphingomonas, Pseudomonas, Sphingobium, Aeromicrobium, and Flavobacterium were the most abundant genera associated with aerobic chemoheterotrophy and chemoheterotrophy (Fig. S6 and S7). Acinetobacter, Candidatus Xiphinematobacter, and Clostridium were the predominant genera associated with animal parasites or symbionts (Fig. S8). Similarly, the dominant genera associated with aromatic compound degradation were Acinetobacter and Rhodococcus (Fig. S9). Bacterial members under the genus Acinetobacter, Clostridium, and Stenotrophomonas showed a higher abundance among the potential human pathogens (Fig. S10).

Though the average abundance was comparatively lesser than the five functions mentioned above, the abundance of bacterial genera associated with functions like oxygenic photoautotrophy, photoautotrophy, and phototrophy was higher in autumn. The genus Synechococcus showed a higher abundance in oxygenic photoautotrophy (Fig. S11). Synechococcus and Rhodoplanes showed a higher 
abundance in photoautotrophy (Fig. S12). Similarly, bacterial members of the genus Synechococcus and Rhodobacter were more abundant in phototrophy (Fig. S13).

\section{Discussion}

\section{The high abundance of Planctomycetes in spring exclusive OTUs}

Our results indicated that many unique OTUs in spring belonged to Planctomycetes. Similarly, Actinobacteria dominated most of the unique OTUs in the autumn.

Though bacterial members of Planctomycetes are reported to be ubiquitous, they are generally dominant in freshwater ecosystems, with the abundance ranging from $<1$ up to $22 \%$ (Andrei et al. 2019). In addition to utilizing a wide range of plant-derived organic substrates, Planctomycetes play a pivotal role in the fractionation of dissolved organic matter in natural water (Tadonléké 2007). Anammox Planctomycetes are used to remove ammonia from wastewater (Wiegand et al. 2018). A study in Porto, a city in Portugal with similar anthropogenic influence, uncovered a higher clone sequence of Planctomycetes in the biofilm of microalgae (Bondoso et al. 2017). The Ramsar site is located in a highly urbanized area of the Central Himalayas, which receives a large amount of municipal wastewater and pollutants. The wastewater inflow in spring is comparatively higher than in autumn as the onset of monsoon is earlier in May. Due to the physiological tolerance of Planctomycetes to heavy metals and their role in wastewater treatment, it is obvious to contribute to the majority of unique OTUs in the spring season. In addition to Planctomycetes, Bacteroidetes also contributed to the high proportion of unique OTUs in spring. Bacteroidetes are fast growers involved in the biodegradation of complex biomolecules (Kirchman 2002). The genus Flavobacterium was the most abundant within this Phylum. Pioneer study in freshwater microbiology publicized that members of the genus Flavobacterium prefer copiotroph lifestyle and proliferate in high nutrient conditions (Newton et al. 2011). Our results also supported this fact, as the spring was when the concentrations of nutrients peaked.

In autumn, the majority of the unique OTUs belonged to Actinobacteria. Actinobacteria possess several hydrolytic enzymes and play a significant role in recycling nutrients in various habitats. Under the phylum Actinobacteria, clade ACK-M1 showed the highest relative abundance. This clade of typical freshwater bacteria (TFB) was associated with higher $\mathrm{pH}$ in freshwater lakes (Lindström et al. 2005). The $\mathrm{pH}$ value of studied sites was significantly higher during the autumn, which may be responsible for the higher abundance of ACK-M1 lineage of phylum Actinobacteria.

\section{Effect of nutrients on bacterial biodiversity}

Our result uncovered that water nutrients were the predominant factors affecting all the bacterial biodiversity indices, including abundance, richness, and community composition. 
In this study, nutrients positively affected bacterial biodiversity indices (abundance, richness, community composition) and lake productivity, with the highest effect value among all latent variables. DOC and TN were used as the latent variables for nutrients. DOC is the readily available form of carbon in the water column of aquatic ecosystems (N. P. Adhikari et al. 2019a, Williamson et al. 2008) derived from both autochthonous and allochthonous sources (Farjalla et al., 2006). Autochthonous DOC derived from phytoplankton and aquatic macrophytes is labile and readily assimilated by bacteria (Søndergaard and Theil-Nielsen, 1997, Weiss and Simon, 1999). It could be associated with many dissolved nutrients released in water that inhabiting heterotrophic bacteria can rapidly be used (Landa et al. 2016).

Meanwhile, allochthonous DOC comprising humic substances with a high $\mathrm{C} / \mathrm{N}$ ratio is associated with lignin components from riparian vegetation (Hedges et al. 1994, Farjalla et al. 2006). Nitrogen is a vital element for all living beings. Having located at the center of the city and surrounded by forest, studied lakes receive DOC from both sources. Nitrogen in aquatic environments is derived from terrestrial landscapes and atmospheric sources. Terrestrial nitrogen sources include domestic, industrial, and agricultural sources (Duce et al. 2008, Xia et al. 2018). In the meantime, atmospheric nitrogen comes via local and long-range transport of nitrogenous pollutants (Boyer et al. 2006). Total nitrogen (TN) is the sum of total Kjeldahl nitrogen (ammonia, nitrite, and nitrate), which are the intermediates of the nitrogen cycle. The positive effect of dissolved nutrients on bacterial richness and abundance is not surprising as we targeted free-living bacteria that rely on dissolved organic matter (Zhao et al. 2017).

Apart from physicochemical parameters and nutrients, the effect of bacterial abundance on bacterial community composition and richness was pronounced, i.e., bacterial abundance as a biological parameter showed the positive and negative impact on bacterial community composition and richness, respectively. Several interaction s between bacteria like predation, competition, and mutualism exist (Xu et al. 2018). As bacterial abundance balances, growth and loss rates are regulated by inorganic nutrients, organic substrates, predation, lysis, temperature, and other factors (Gurung et al. 2010), its effect on microbial biodiversity is also expected. A study in an alpine glacier-fed water body of the Tibetan Plateau also uncovered the impact of bacterial abundance on bacterial community composition and OTU richness (Liu et al. 2017).

The result of DISTLM_forward indicated that temperature and TDS significantly explained the variation of bacterial community composition, with a cumulative percentage variation of 26.25 . Temperature is often associated with bacterial biodiversity as it directly relates to metabolic rates and the affinity of bacteria to available substrates (Nedwell 1999, Paudel Adhikari et al. 2019). Similarly, TDS measures the sum of all the dissolved ions present in an aqueous medium (Khadka and Ramanathan 2013, Adhikari et al. 2020, Kaphle et al. 2021) that can directly or indirectly affect the bacterial community composition. The value of TDS peaked during autumn due to the concentration of ionic species. Since we targeted FL-bacteria, our result is not surprising. 


\section{The high abundance of pathogenic bacteria implies public health attention}

FAPROTAX based functional analysis showed metabolic and functional potentials of abundant bacteria in lakes. Furthermore, many inhabiting bacteria were animal parasites and human pathogens, indicating a severe public health threat.

In our study, the abundance of pathogen-associated bacteria was comparatively higher in spring/ May. The region receives maximum precipitation in Nepal (Dahal et al. 2016), and the onset of monsoon starts earlier in May. Previous studies revealed that the influx of contaminated water from streams to lakes and reservoirs could substantially increase pathogen levels (Kistemann et al. 2002, Fisher et al. 2015). As the nearby land is highly influenced by anthropogenic activities like sewage drainage, agricultural practices, urbanization, fishing, boating, and recreation (Paudel et al. 2017), many pathogens can be introduced to the lake.

Acinetobacter, Clostridium, and Stenotrophomonas were the three top genera associated with pathogenic potential. These bacteria have been isolated from diverse habitats. Acinetobacter spp. is an opportunistic pathogen and can potentially cause nosocomial infections like septicemia, pneumonia, meningitis, urinary tract infections, skin and wound infections in immunocompromised patients (Regalado et al. 2009, Yang et al. 2019). Clostridium spp. is a Gram-positive, spore-forming, and anaerobic bacteria predominantly found in soil. They cause a wide range of infections to humans, i.e., tetanus, food poisoning, and gas gangrene. Stenotrophomonas spp. are environmental bacteria found in soil and aquatic habitats, capable of causing opportunistic infections such as endocarditis, urinary infections, and respiratory infections, including pneumonia in patients with cystic fibrosis (Sánchez 2015). Thus, the higher abundance of pathogenic bacteria in lakes reflects that the lakes are polluted by pathogens and rapidly transmit diseases to the individuals involved in local activities associated with lake water.

The current study is first-hand work regarding the microbiological studies in the Ramsar site of central Himalayas, Nepal, using the high coverage next-generation sequencing method. This study insight the structure and distribution of bacterial community composition in autumn and spring in anthropogenically influenced Ramsar site of Nepal. Our results characterized the distinct bacterial communities, diversity, and water characteristics (temperature, $\mathrm{pH}, \mathrm{Chl}$ a, DOC, and TN) in autumn and spring. Changes in water nutrients and physicochemical properties in different seasons endorsed bacterial abundance, community composition, and diversity variation, and the variation is attributed to different functions. This helps to understand the microbial ecology in response to urbanization by revealing environmental changes. The ecological processes shaping bacterial communities are essential for microbial ecology and biogeography wetlands. Therefore, the current study will provide a framework of wetlands microbial ecology and critical factors that assist in understanding anthropogenic influence on wetlands biodiversity.

\section{Declarations}


Author's contribution

Study design: Namita Paudel Adhikari and Yongqin Liu. Collection and processing of samples: Subash Adhikari, Birendra Prasad Sharma, and Ganesh Paudel. Experimental work: Namita Paudel Adhikari.

Bioinformatics and statistical analysis: Namita Paudel Adhikari, Subash Adhikari, Keshao Liu, and Yuying Chen. Interpretation of the data: Namita Paudel Adhikari, Yongqin Liu, Subash Adhikari, Keshao Liu, and Yuying Chen. Drafting and revision of the manuscript: Namita Paudel Adhikari and Yongqin Liu.

\section{Funding}

The Strategic Priority Research Program (A) of the Chinese Academy of Sciences (Grant No. XDA20050101 and XDA19070304) funded this research, the Second Tibetan Plateau Scientific Expedition and Research (STEP) program (Grant No.2019QZKK0503), and the National Natural Science Foundation of China (Grant No. 42006200, 91851207) financially supported this work.

\section{Conflict of interest}

The authors declare that they have no known competing financial interests or personal relationships that could have influenced the work reported in this paper.

\section{Data availability}

The datasets used and analyzed during the current study are available from the corresponding author on reasonable request.

\section{Acknowledgement}

We extend our gratitude to China's Chinese Academy of Sciences and National Natural Science Foundation for financially supporting this study.

\section{References}

1. Adhikari NP, Adhikari S, Liu X et al (2019) Bacterial Diversity in Alpine Lakes: A Review from the Third Pole Region. J Earth Sci 30:387-396. doi: 10.1007/s12583-018-1206-5

2. Adhikari S, Zhang F, Adhikari NP et al (2021) Atmospheric wet deposition of major ionic constituents and inorganic nitrogen in Bangladesh: Implications for spatiotemporal variation and source apportionment. Atmos Res 250:105414. doi: 10.1016/j.atmosres.2020.105414

3. Adhikari S, Zhang F, Zeng C et al (2020) Precipitation chemistry and stable isotopic characteristics at Wengguo in the northern slopes of the Himalayas. J Atmos Chem 76:289-313. doi: 10.1007/s10874-020-09399-1

4. Anderson MJ (2001) A new method for non-parametric multivariate analysis of variance. Austral Ecol 26:32-46 
5. Andrei A, Salcher MM, Mehrshad M et al (2019) Niche-directed evolution modulates genome architecture in freshwater Planctomycetes. ISME J 13:1056-1071. doi: 10.1038/s41396-018-0332-5

6. Bodelier PLE, Dedysh SN (2013) Microbiology of wetlands. Front Microbiol 4:2-5. doi: 10.3389/fmicb.2013.00079

7. Bondoso J, Godoy-Vitorino F, Balagué V et al (2017) Epiphytic Planctomycetes communities associated with three main groups of macroalgae. FEMS Microbiol Ecol 93:1-9. doi: 10.1093/femsec/fiw255

8. Caporaso JG, Kuczynski J, Stombaugh J et al (2010) QIIME allows analysis of high-throughput community sequencing data. Nat Methods 7:335-336. doi: 10.1038/nmeth.f.303.QIIME

9. Caporaso JG, Lauber CL, Walters WA et al (2012) Ultra-high-throughput microbial community analysis on the Illumina HiSeq and MiSeq platforms. ISME J 6:1621-1624. doi: 10.1038/ismej.2012.8

10. Carpenter SR, Stanley EH, Vander Zanden MJ (2011) State of the World's Freshwater Ecosystems: Physical, Chemical, and Biological Changes. Annu Rev Environ Resour 36:75-99. doi: 10.1146/annurev-environ-021810-094524

11. Chen H, Boutros PC (2011) VennDiagram: A package for the generation of highly-customizable Venn and Euler diagrams in R. BMC Bioinformatics 12:35. doi: 10.1186/1471-2105-12-35

12. Chen $\mathrm{S}, \mathrm{He} \mathrm{H}$, Zong R et al (2020) Geographical patterns of algal communities associated with different urban lakes in China. Int J Environ Res Public Health 17:1-19. doi: 10.3390/ijerph17031009

13. Crump BC, Armbrust EV, Baross JA (1999) Phylogenetic Analysis of Particle-Attached and Free-Living Bacterial Communities in the Columbia River, Its Estuary, and the Adjacent Coastal Ocean. 65:31923204

14. Dahal P, Shrestha NS, Shrestha ML et al (2016) Drought risk assessment in central Nepal: temporal and spatial analysis. Nat Hazards 80:1913-1932. doi: 10.1007/s11069-015-2055-5

15. Dai Y, Yang Y, Wu Z et al (2015) Spatiotemporal variation of planktonic and sediment bacterial assemblages in two plateau freshwater lakes at different trophic status. 10.1007/s00253-015-72532

16. Edgar RC (2010) Search and clustering orders of magnitude faster than BLAST. Bioinformatics 26:2460-2461. doi: 10.1093/bioinformatics/btq461

17. Farjalla VF, Azevedo DA, Esteves FA et al (2006) Influence of hydrological pulse on bacterial growth and DOC uptake in a clear-water Amazonian lake. Microb Ecol 52:334-344. doi: 10.1007/s00248006-9021-4

18. Fisher JC, Newton RJ, Dila DK, McLellan SL (2015) Urban microbial ecology of a freshwater estuary of Lake Michigan. Elementa 3:1-14. doi: 10.12952/journal.elementa.000064

19. Gurung TB, Dhakal RP, Husen MA, Jones JR (2010) Abundance and nutrient limiting growth rate of heterotrophic bacterio-plankton in Himalayan foot hill Lake Phewa, Nepal. Lakes and Reservoirs: Research and Management 15:53-61. doi: 10.1111/j.1440-1770.2010.00422.x 
20. Hahn MW (2006) The microbial diversity of inland waters. Curr Opin Biotechnol 17:256-261. doi: 10.1016/j.copbio.2006.05.006

21. Hammer $\varnothing$, Harper DAT, Ryan PD (2001) PAST:Paleontoplogical Statistics Software Package for Education and Data Analysis. Palaeontologia Electronica 4:1-9

22. Hedges JI, Cowie GL, Richey JE et al (1994) Origins and processing of organic matter in the Amazon River as indicated by carbohydrates and amino acids. Limnol Oceanogr 39:743-761. doi: 10.4319/lo.1994.39.4.0743

23. Huang LL, Kou WB, Wu L (2018) Microbial Composition and Activity of Natural, Restored, and Reclaimed Wetland Soils. a Case Study of Poyang Lake, Wetlands

24. Kaphle B, Wang J, Kai J et al (2021) Hydrochemistry of Rara Lake: A Ramsar lake from the southern slope of the central Himalayas, Nepal. J Mt Sci 18:141-158. doi: 10.1007/s11629-019-5910-0

25. Khadka UR, Ramanathan AL (2013) Major ion composition and seasonal variation in the Lesser Himalayan lake: Case of Begnas Lake of the Pokhara Valley, Nepal. Arab J Geosci 6:4191-4206. doi: $10.1007 /$ s12517-012-0677-4

26. Kirchman DL (2002) The ecology of Cytophaga-Flavobacteria in aquatic environments. FEMS Microbiol Ecol 39:91-100

27. Kistemann T, Claßen T, Koch C et al (2002) Microbial load of drinking water reservoir tributaries during extreme rainfall and runoff. Appl Environ Microbiol 68:2188-2197. doi: 10.1128/AEM.68.5.2188-2197.2002

28. Konda T, Nakanishi M, Sako Y et al (1988) Bacterial Numbers and Floras in the Water Sediment of Subtropical Lakes Phewa, Begnas and Rupa in Nepal. Bulletin of Japanese Society of Microbial Ecology 3:21-28

29. Kong Z, Kou W, Ma Y et al (2018) Seasonal dynamics of the bacterioplankton community in a large, shallow, highly dynamic freshwater lake. Can J Microbiol 797:786-797

30. Lindström ES, Agterveld MPK, Zwart G et al (2005) Distribution of Typical Freshwater Bacterial Groups Is Associated with pH, Temperature, and Lake Water Retention Time Distribution of Typical Freshwater Bacterial Groups Is Associated with $\mathrm{pH}$, Temperature, and Lake Water Retention Time. Appl Environ Microbiol 71:8201-8206. doi: 10.1128/AEM.71.12.8201

31. Liu K, Liu Y, Jiao N et al (2017) Bacterial community composition and diversity in Kalakuli, an alpine glacial-fed lake in Muztagh Ata of the westernmost Tibetan Plateau. FEMS Microbiology Ecology. 10.1093/femsec/fix085

32. Louca S, Parfery LW, Doebeli M (2016) Decoupling function and taxonomy in the global ocean microbiome. Science 353:1272-1277. doi: 10.1126/science.aaf4507

33. MacFarland TW YJM (2016) Kruskal-Wallis H-Test for Oneway Analysis of Variance (ANOVA) by Ranks. Introduction to Nonparametric Statistics for the Biological Sciences Using R. 10.1007/978-3319-30634-6

34. Mago c T, Salzberg SL (2011) FLASH: fast length adjustment of short reads to improve genome assemblies. Bioinformatics 27:2957-2963. doi: 10.1093/bioinformatics/btr507 
35. Nedwell D (1999) Effect of low temperature on microbial growth: lowered affinity for substrates limits growth at low temperature. FEMS Microbiol Ecol 30:101-111. doi: 10.1111/j.15746941.1999.tb00639.x

36. Newton RJ, Jones SE, Eiler A et al (2011) A Guide to the Natural History of Freshwater Lake Bacteria †. 10.1128/MMBR.00028-10

37. Panthi J, Dahal P, Shrestha ML et al (2015) Spatial and Temporal Variability of Rainfall in the Gandaki River Basin of Nepal Himalaya. Climate 3:210-226. doi: 10.3390/cli3010210

38. Paudel Adhikari N, Liu Y, Liu K et al (2019) Bacterial community composition and diversity in Koshi River, the largest river of Nepal. Ecol Ind 104:501-511. doi: 10.1016/j.ecolind.2019.05.009

39. Paudel N, Adhikari S, Paudel G (2017) Ramsar Lakes in the Foothills of Himalaya, PokharaLekhnath, Nepal: an overview. Janapriya Journal of Interdisciplinary Studies 6:134-147. doi: 10.3126/jjis.v6i0.19315

40. Pendleton MC, Sedgwick S, Kettenring KM, Atwood TB (2020) Ecosystem Functioning of Great Salt Lake Wetlands

41. Regalado NG, Martin G, Antony SJ (2009) Acinetobacter Iwoffii: Bacteremia associated with acute gastroenteritis. Travel Med Infect Dis 7:316-317. doi: 10.1016/j.tmaid.2009.06.001

42. Sanchez G (2013) PLS Path Modeling with R G aston S anchez

43. Sánchez MB (2015) Antibiotic resistance in the opportunistic pathogen Stenotrophomonas maltophilia. Front Microbiol 6:1-7. doi: 10.3389/fmicb.2015.00658

44. Sansupa C, Wahdan SFM, Hossen S et al (2021) Can we use functional annotation of prokaryotic taxa (Faprotax) to assign the ecological functions of soil bacteria? Applied Sciences (Switzerland) 11:1-17. doi: 10.3390/app11020688

45. Sigee DC (2005) Freshwater Microbiology. John Wiley \& Sons Ltd. The Atrium, Southern Gate, Chichester, West Sussex P019 8SQ, England

46. Staley C, Unno T, Gould TJ et al (2013) Application of Illumina next-generation sequencing to characterize the bacterial community of the Upper Mississippi River. 10.1111/jam.12323

47. Tadonléké RD (2007) Strong coupling between natural Planctomycetes and changes in the quality of dissolved organic matter in freshwater samples. FEMS Microbiol Ecol 59:543-555. doi: 10.1111/j.1574-6941.2006.00222.x

48. Tang X, Li L, Shao K et al (2015) Pyrosequencing analysis of free-living and attached bacterial communities in Meiliang Bay, Lake Taihu, a large eutrophic shallow lake in China. Can J Microbiol 61:22-31. doi: 10.1139/cjm-2014-0503

49. Team RC (2014) R: A language and environment for statistical computing. R: A language and environment for statistical computing. R Foundation for Statistical Computing, Vienna, Austria. doi: 10.1530/EJE-14-0355

50. Wang J, Feiyan P, Soininen J et al (2016) Nutrient enrichment modifies temperature-biodiversity relationships in large-scale field experiments. Nat Commun 7:1-9. doi: 10.1038/ncomms13960 
51. Wiegand S, Jogler M, Jogler C (2018) On the maverick Planctomycetes. FEMS Microbiol Rev 42:739760. doi: $10.1093 /$ femsre/fuy029

52. Xu H, Zhao D, Huang R et al (2018) Contrasting Network Features between Free-Living and ParticleAttached Bacterial Communities in Taihu Lake. Microb Ecol 76:303-313. doi: 10.1007/s00248-0171131-7

53. Yang $Y$, Hou Y, Ma M, Zhan A (2019) Potential pathogen communities in highly polluted river ecosystems: Geographical distribution and environmental influence. Ambio doi. 10.1007/s13280019-01184-z

54. Zeng J, Lin Y, Zhao D et al (2019) Seasonality overwhelms aquacultural activity in determining the composition and assembly of the bacterial community in Lake Taihu, China. Sci Total Environ 683:427-435. doi: 10.1016/j.scitotenv.2019.05.256

55. Zhang $\mathrm{H}$, Wang $\mathrm{Y}$, Chen $\mathrm{S}$ et al (2018) Water bacterial and fungal community compositions associated with urban lakes, Xi'an, China. Int J Environ Res Public Health. doi: 10.3390/ijerph15030469

56. Zhao D, Xu H, Zeng J et al (2017) Community composition and assembly processes of the free-living and particle-attached bacteria in Taihu Lake. FEMS Microbiol Ecol 93:1-10. doi: 10.1093/femsec/fix062

\section{Tables}

TABLE 1 The distance-based multivariate linear model of bacterial community composition and the percentage variance explained by measured environmental variables and nutrients (sequential test, 999 permutations). Data in bold indicate significant correlations i.e. $(P<0.05)$. TDS: total dissolved solids, EC: electrical conductivity, TN: total nitrogen, DOC: dissolved organic carbon, Chl a: Chlorophyll a

\begin{tabular}{|c|c|c|c|c|}
\hline \multirow[t]{2}{*}{ Variables } & \multirow[t]{2}{*}{ Pseudo-F } & \multirow[t]{2}{*}{$P$} & Percentage & \multirow{2}{*}{$\begin{array}{l}\text { Cumulative variation } \\
\text { explained }\end{array}$} \\
\hline & & & $\begin{array}{l}\text { variation } \\
\text { explained }\end{array}$ & \\
\hline Temperature & 3.8637 & 0.0001 & 19.45 & 19.45 \\
\hline TDS & 1.3822 & 0.010 & 6.80 & 26.25 \\
\hline $\mathrm{pH}$ & 1.2408 & 0.106 & 6.00 & 32.25 \\
\hline EC & 1.1678 & 0.258 & 5.58 & 37.83 \\
\hline $\mathrm{TN}$ & 0.8597 & 0.627 & 4.16 & 41.99 \\
\hline DOC & 0.0601 & 0.411 & 5.10 & 47.09 \\
\hline Chl a & 0.5479 & 0.917 & 2.75 & 49.89 \\
\hline
\end{tabular}




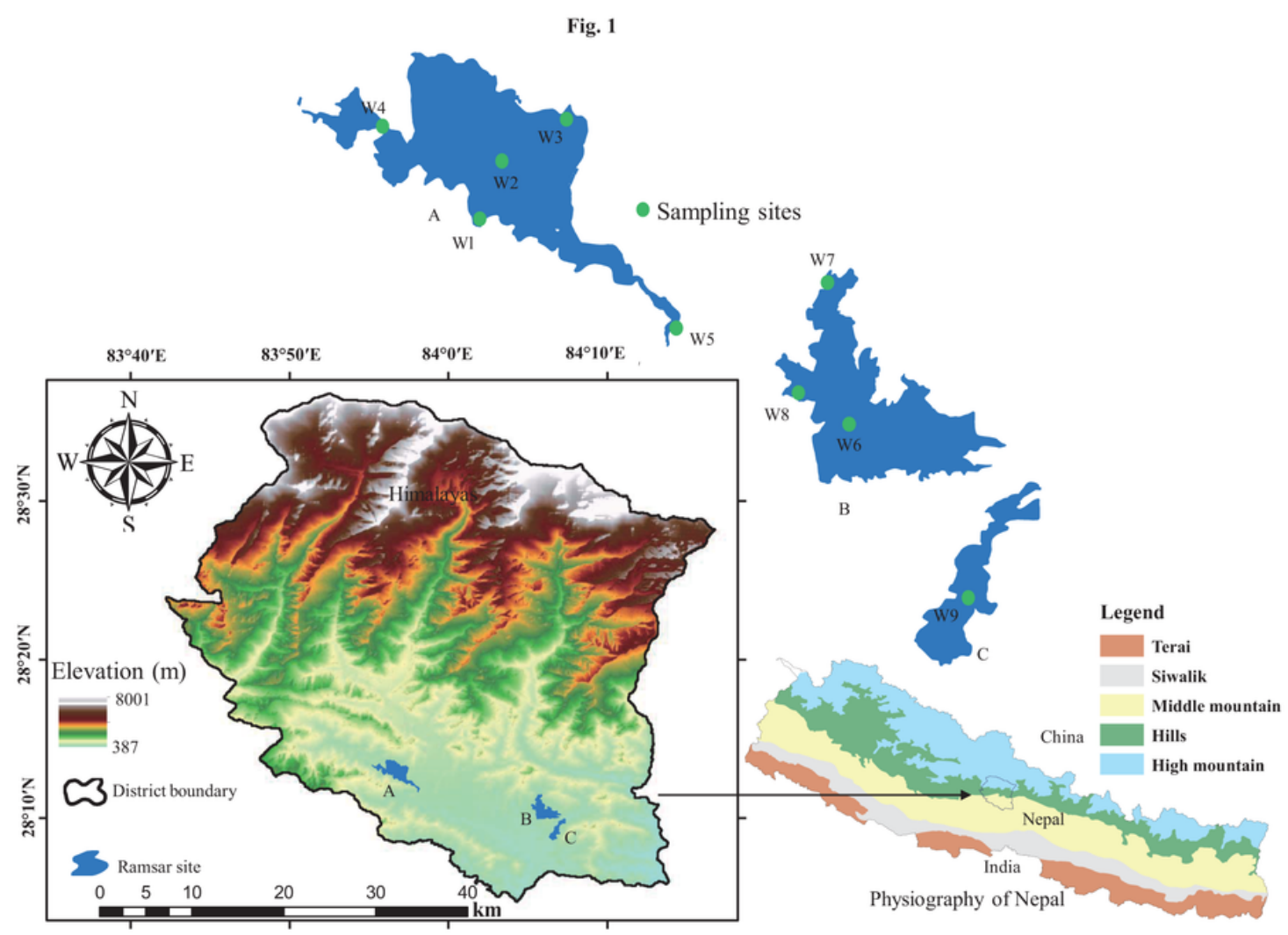

Figure 1

Location map of wetlands at foothills of the Himalayas, Nepal showing water sampling sites 
Fig. 2
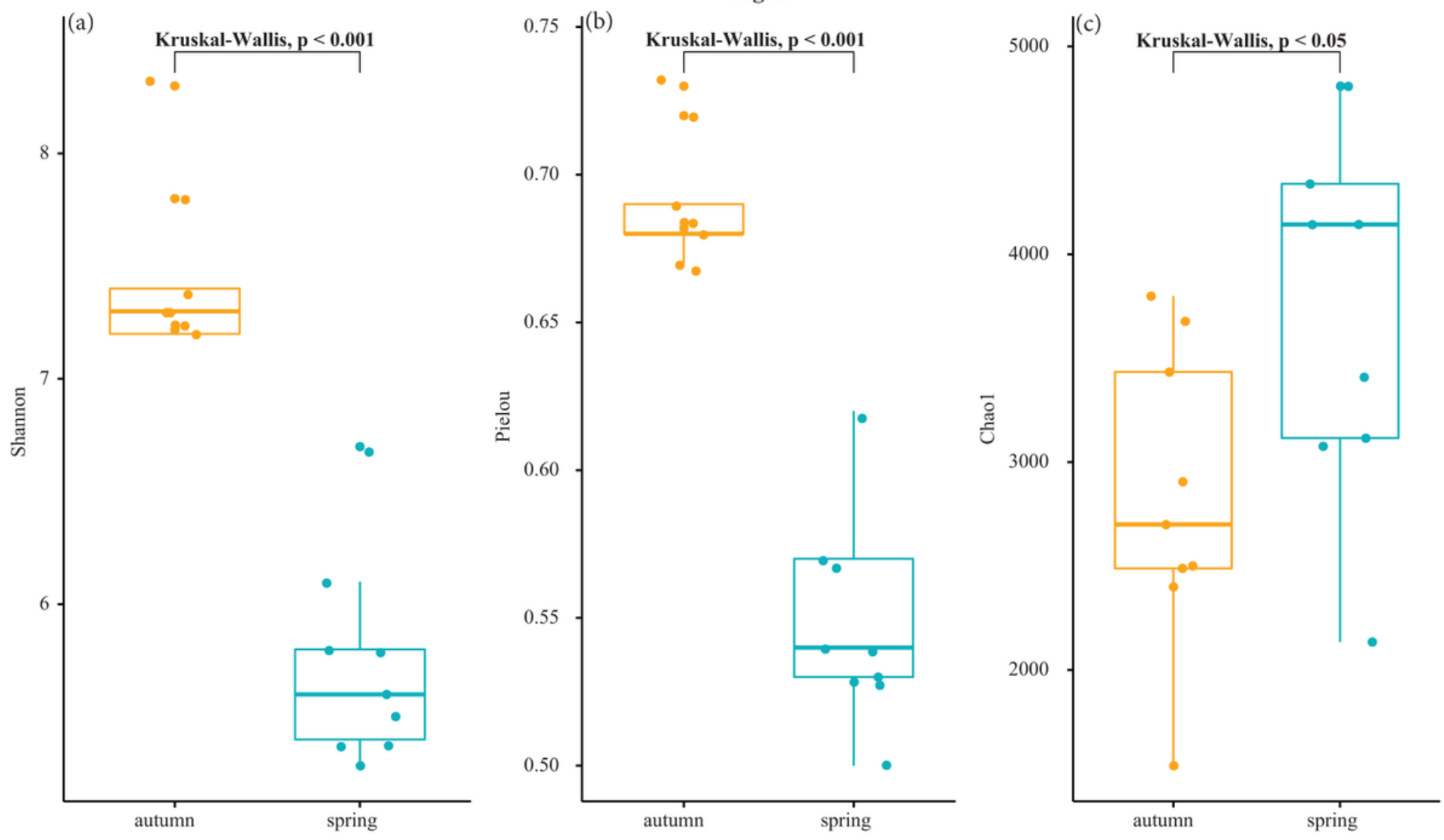

Figure 2

Boxplots comparing a-diversity indices in autumn and spring. (a) Shannon index, (b) Pielou's evenness, (c) Chao1 richness. Dots represent individual data points. Illustrated $P$-value is based on the KruskalWallis test 
Fig. 3
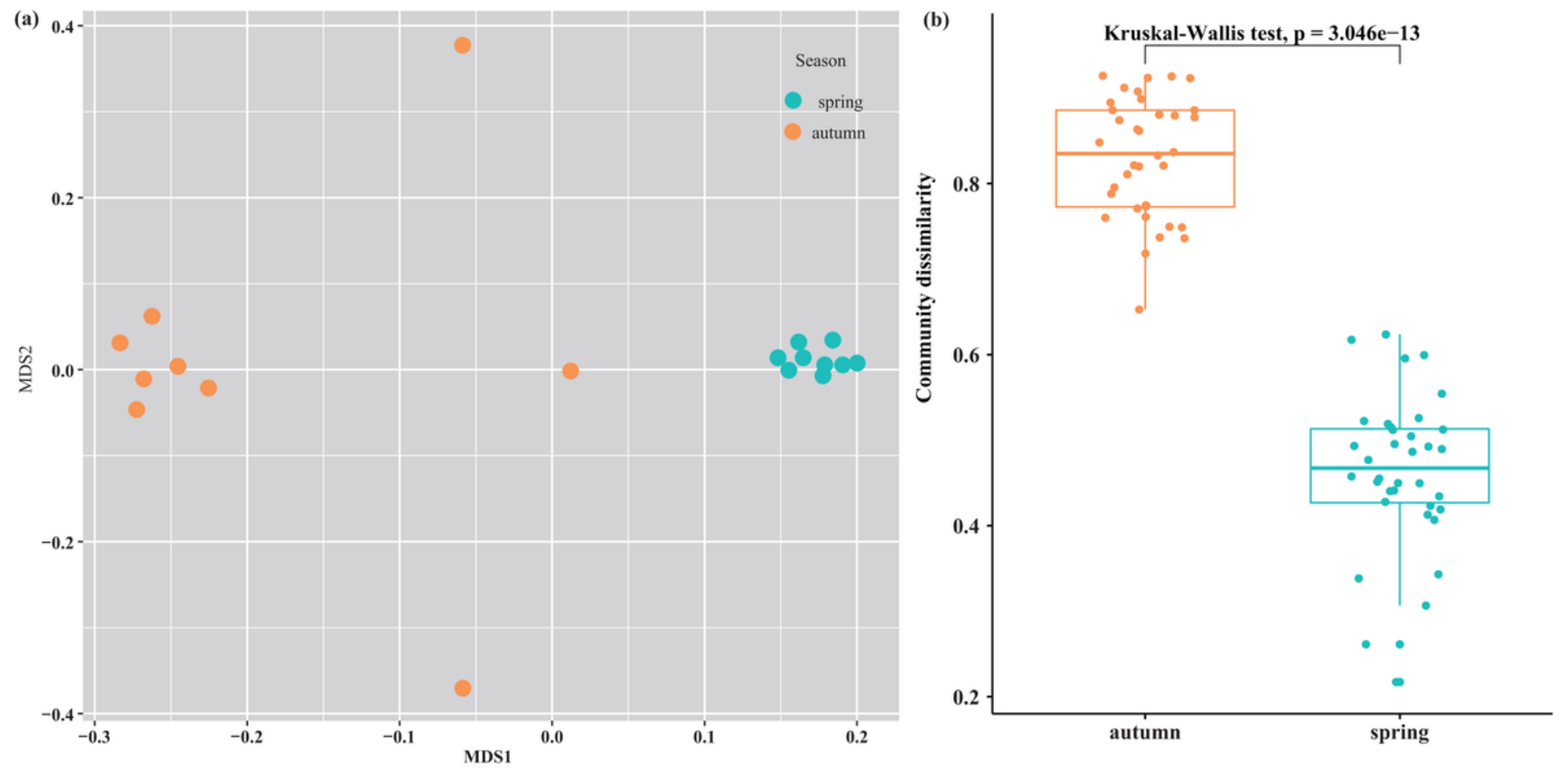

Figure 3

NMDS ordination (a) and boxplots (b) of the dissimilarity between autumn and spring bacterial communities based on Bray-Curtis distance 


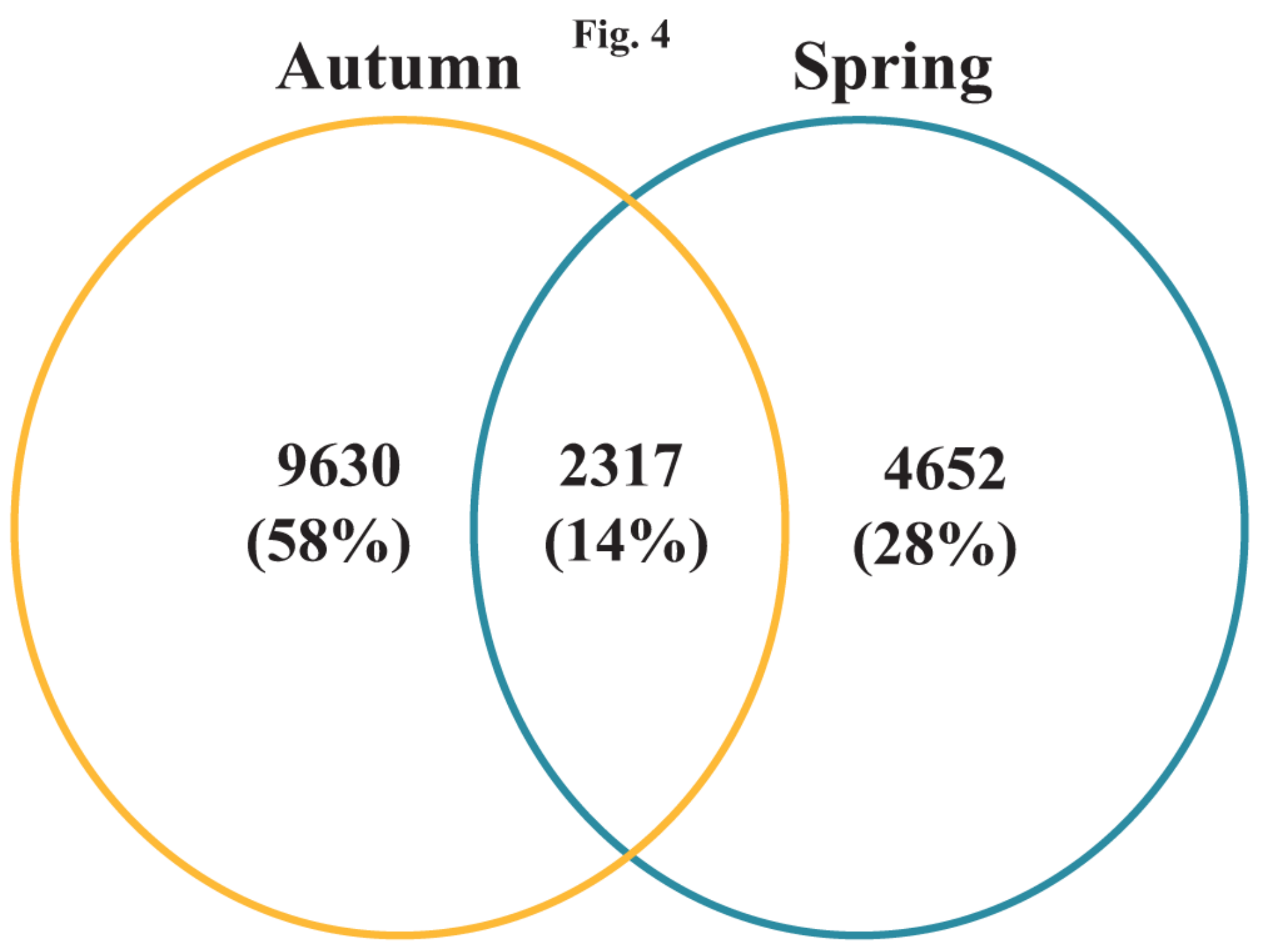

Figure 4

Venn diagram showing the number of shared and unique OTUs in spring and autumn 
(a) Shared in Spring and Autumn

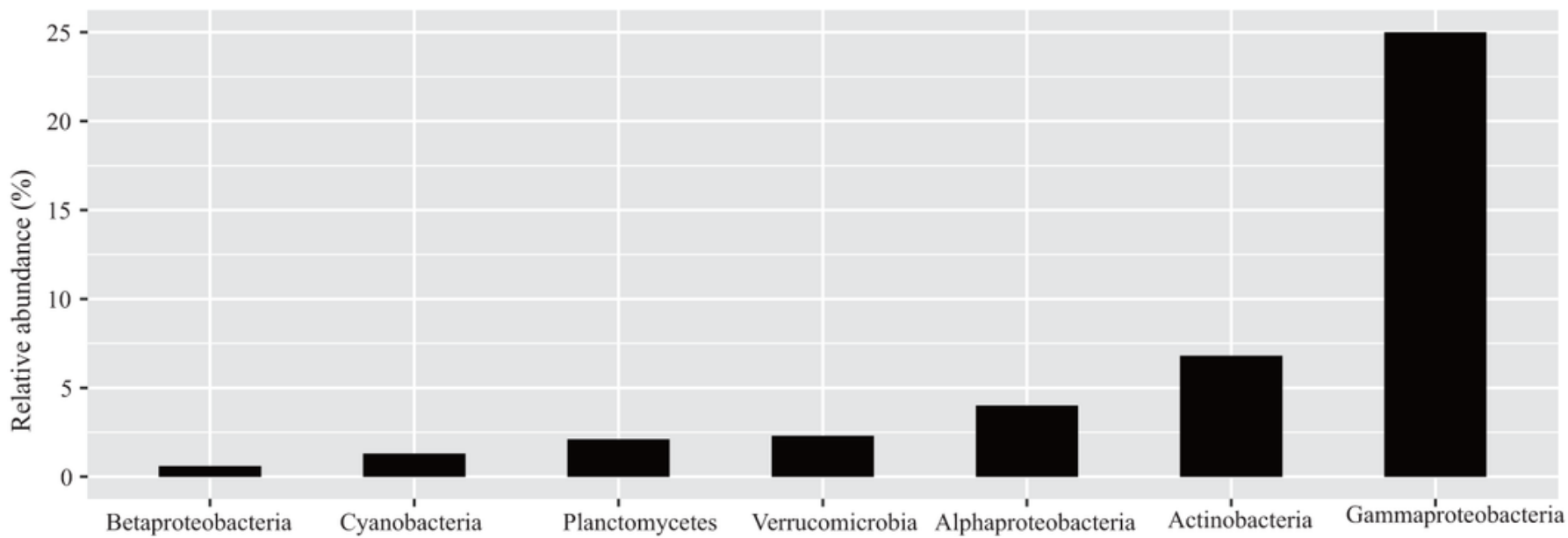

(b) Unique in autumn

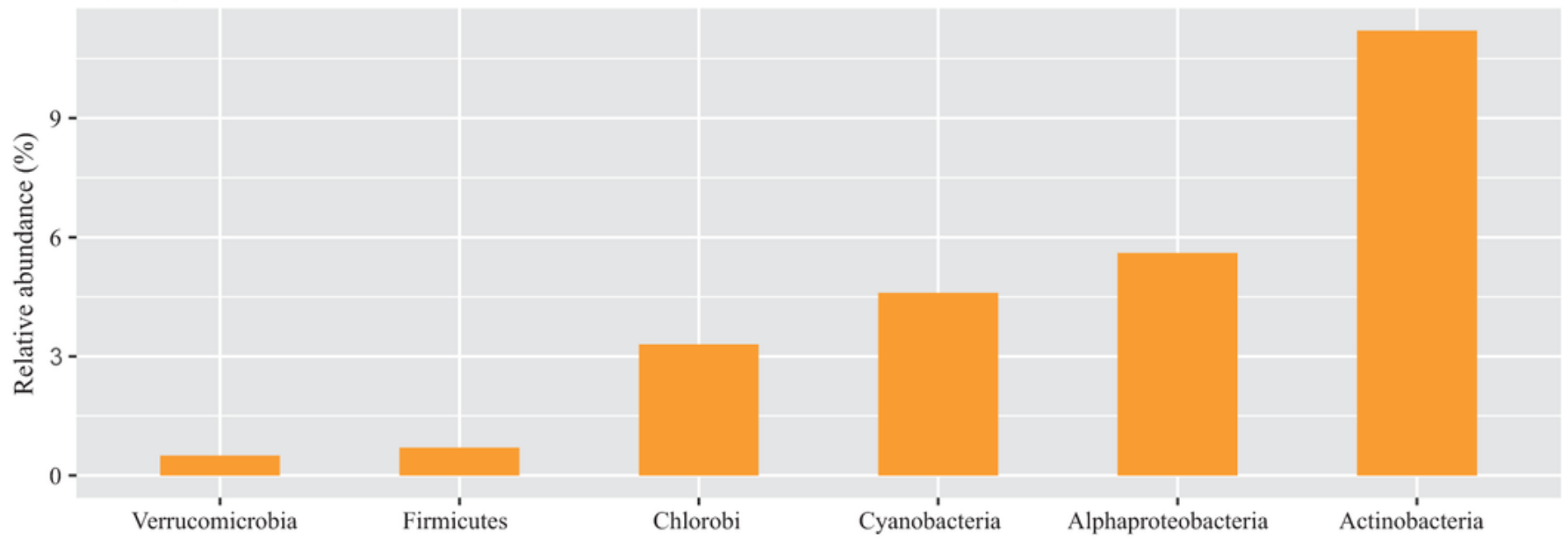

(c) Unique in spring

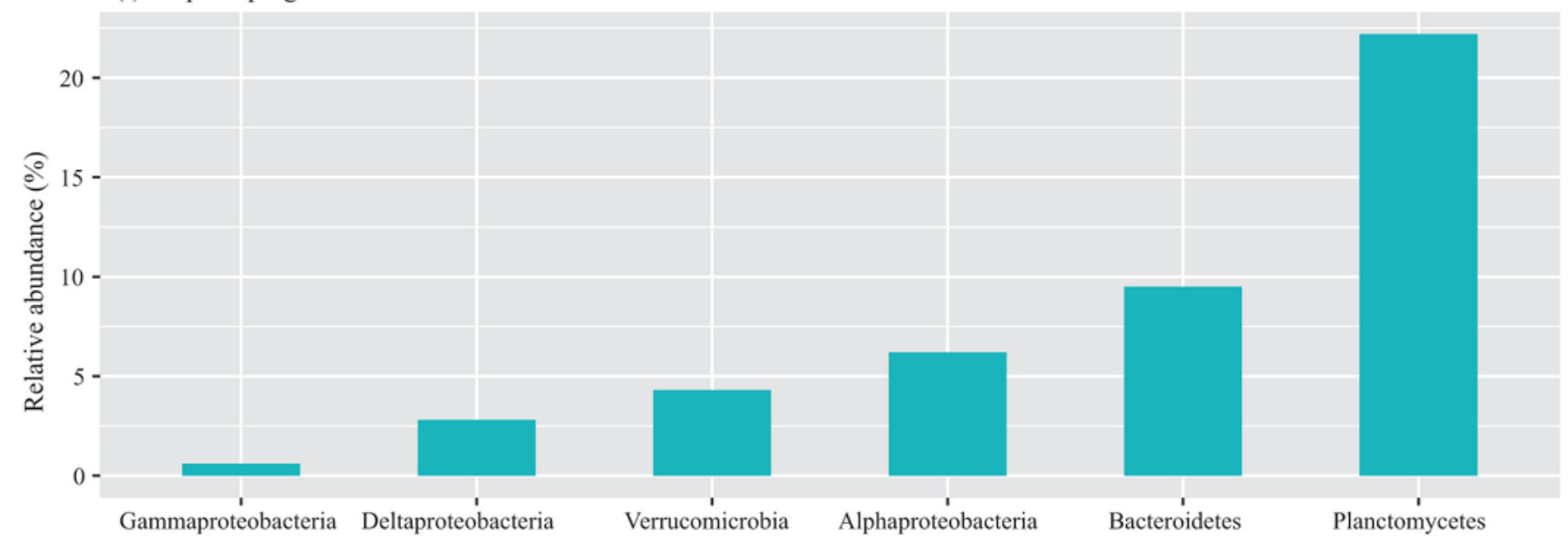

Figure 5

Mean relative abundance (\%) of each phylum/class affiliated in shared (a) and unique OTUs (b-c). Only the taxa with a mean relative abundance of over $1 \%$ are displayed 


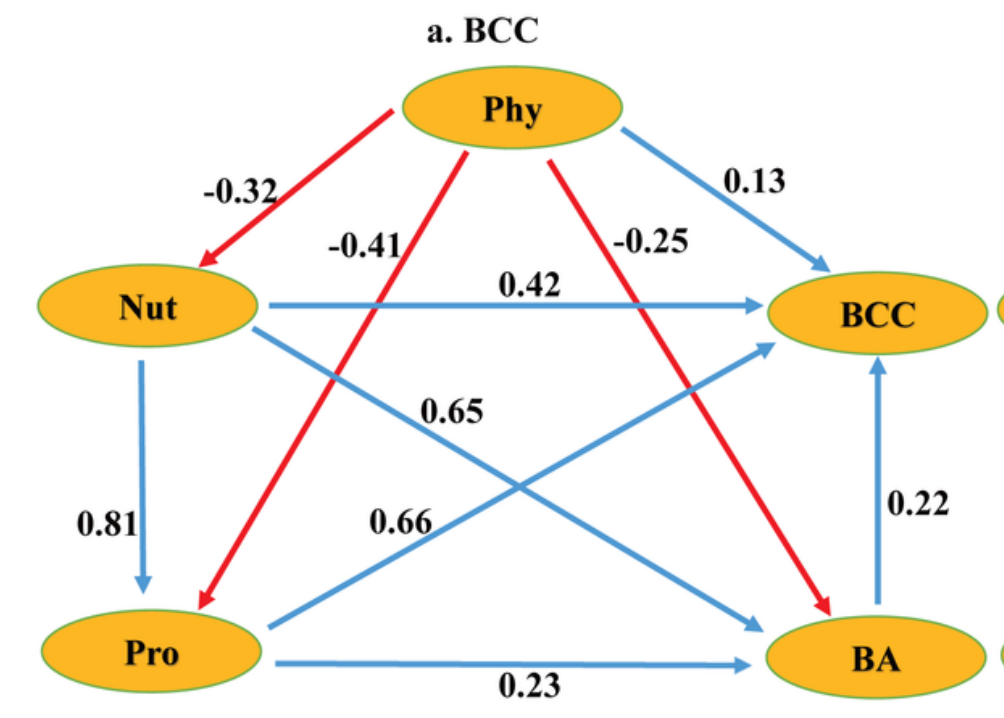

Fig. 6

b. Richness

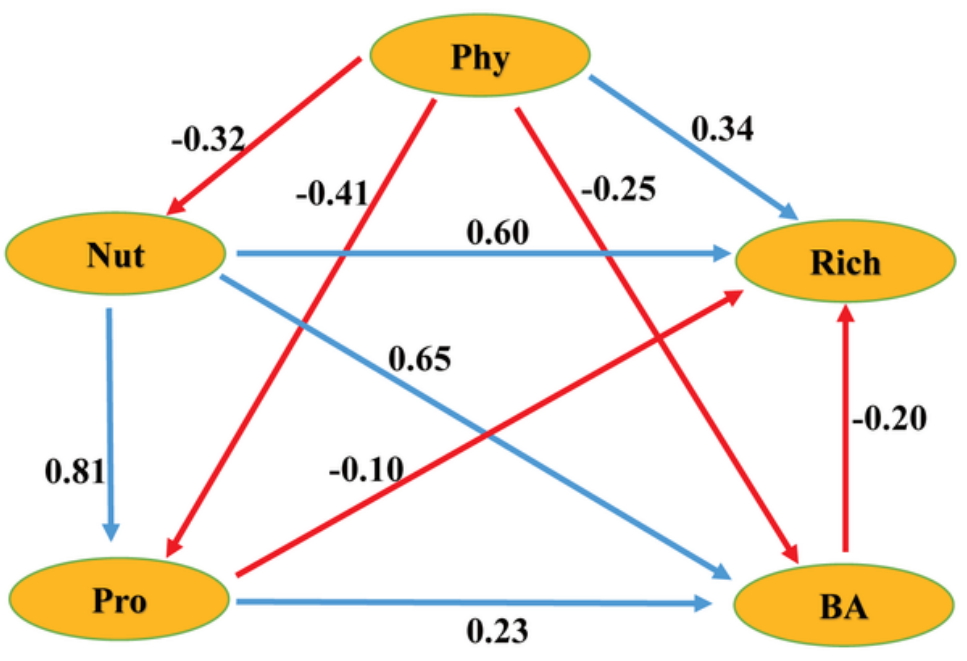

Figure 6

Structural equation modelling showing the effects of temperature, nutrients, and lake primary productivity on biodiversity. The effects of water physicochemical properties (Phy), nutrient enrichment (Nut), primary productivity (Pro), and bacterial abundance (BA) on diversity bacterial community composition (a) and richness (b) as explored by partial least squares path model. The measured water temperature, $\mathrm{pH}, \mathrm{EC}$, and TDS were used as the observed variables for water physicochemical properties. DOC and TN were used as the observed variables for nutrients. Chla was used as the observed variable for primary lake productivity. The GoFs for (a) and (b) are 0.54 and 0.52 , respectively 


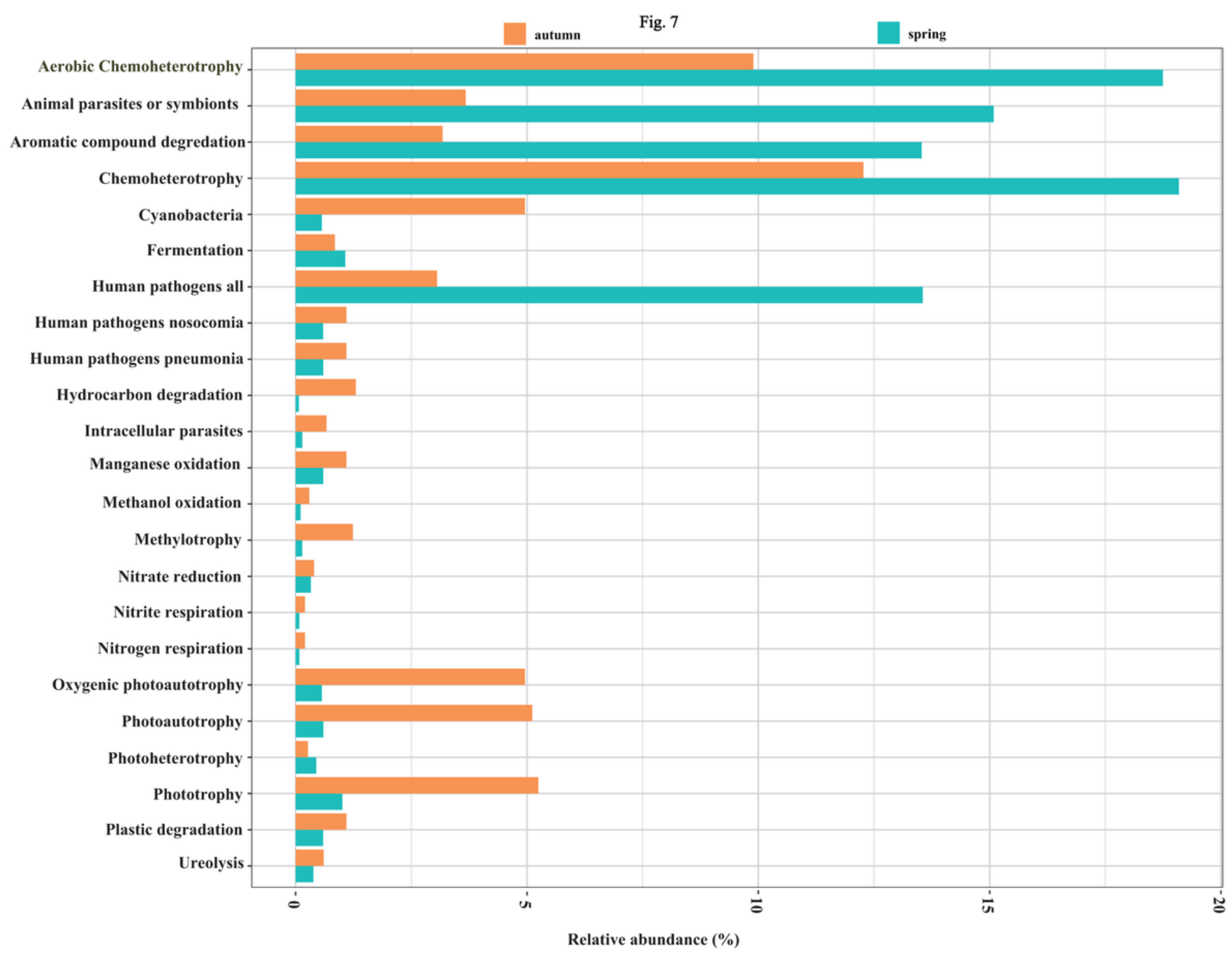

Figure 7

Relative abundance of OTUs associated with different putative functions in spring and autumn based on FAPROTAX

\section{Supplementary Files}

This is a list of supplementary files associated with this preprint. Click to download.

- Supplementarymaterial.docx 